\title{
Effect of antibodies to intercellular adhesion molecule type 1 on the protection of distant organs during reperfusion syndrome in rats
}

M.R. Souza-Moraes ${ }^{1}$, R. David-Filho ${ }^{1}$, J.C.C. Baptista-Silva ${ }^{1}$, M. Ullian², M.F. Franco ${ }^{3}$, A. Gabriel Jr. ${ }^{2}$, B. Smith ${ }^{3}$ and E. Burihan ${ }^{1}$

\author{
Departamentos de ${ }^{1}$ Cirurgia, ${ }^{2}$ Clínica and ${ }^{3}$ Patologia, \\ Escola Paulista de Medicina, Universidade Federal de São Paulo, \\ São Paulo, SP, Brasil
}

Correspondence
M.R. Souza-Moraes
Rua Duarte Leite, 121
Granja Julieta
04720-070 São Paulo, SP
Brasil
Fax: +55-11-5181-3109
E-mail: mrsmoraes@zipmail.com.br

Publication supported by FAPESP.

Received February 25, 2002 Accepted February 20, 2003

\begin{abstract}
We investigated kidney and lung alterations caused by intercellular adhesion molecule type 1 (ICAM-1) blockade after ischemia and reperfusion of hind limb skeletal muscles. Rats were submitted to ligature of the infrarenal aorta for $6 \mathrm{~h}$. The animals were randomized into three groups of 6 rats each: group I, sacrificed after ischemia; group II, reperfusion for $24 \mathrm{~h}$, and group III, reperfusion for $24 \mathrm{~h}$ after receiving monoclonal anti-ICAM-1 antibodies. At the end of the experiment, blood samples were collected for creatinine, lactate dehydrogenase, creatine phosphokinase, potassium, $\mathrm{pH}$ and leukocyte counts. Samples were taken from the muscles of the hind limbs and from the kidneys and lungs for histological analysis and measurement of the neutrophil infiltrate by myeloperoxidase staining. The groups did not differ significantly with regard to the laboratory tests. There were no major histological alterations in the kidneys. An intense neutrophil infiltrate in the lungs, similar in all groups, was detected. Myeloperoxidase determination showed that after reperfusion there was significantly less retention of polymorphonuclear neutrophils in the muscles $\left(352 \pm 70\right.$ vs $1451 \pm 235 \times 10^{2}$ neutrophils $\left./ \mathrm{mg} ; \mathrm{P}<0.01\right)$ and in the kidneys ( $526 \pm 89$ vs $852 \pm 73 \times 10^{2}$ neutrophils $\left./ \mathrm{mg} ; \mathrm{P}<0.01\right)$ of the animals that received anti-ICAM-1 before perfusion compared to the group that did not. The use of anti-ICAM-1 antibodies in this experimental model minimized neutrophil influx, thus reducing the inflammatory process, in the muscles and kidneys after ischemia and reperfusion of the hind limbs.
\end{abstract}

\section{Introduction}

During the first half of the 20th century, studies that associated extensive traumatic muscle lesions with a syndrome represented by dark urine (myoglobinuria), muscle pain,
Key words

- ICAM-1

- Neutrophil

- Myeloperoxidase

- Kidney

- Lung

- Reperfusion 
patients suffering from arterial occlusion and trauma that cause ischemia and reperfusion of the limbs. Despite advances in medical knowledge and technology, little progress has been made in the treatment of such patients. This syndrome presents a high mortality rate, especially when associated with specific pathological conditions such as diabetes, senility, renal insufficiency and others (3). Recently many authors began to investigate the role of oxygen (4) and its toxic derivatives $(5,6)$, polymorphonuclear neutrophils (PMN; 7-9) and the intercellular adhesion molecule type 1 (ICAM-1) in ischemia and reperfusion $(10,11)$.

The aim of the present study was to attenuate the negative effects of reperfusion that frequently affect organs distant from the site of injury, more frequently kidneys (12) and lungs (13). We evaluated the effect of ICAM-1 blockade with antibodies on the rat hind limb reperfusion syndrome especially on kidneys and lungs.

\section{Material and Methods}

The study utilized adult Wistar EPM-1 rats from the Central Animal House of UNIFESP-EPM, aged 90 to 120 days and weighing 250 to $350 \mathrm{~g}$. Ethical principles for animal experimentation as stated by the International Animal Protection Union and Law 6638 of May 1979, and revised in 1983 were strictly followed. The protocol was submitted to the Research Ethics Committee of UNIFESP-EPM, and approved (No. 239/01).

\section{Surgical technique}

Eighteen animals received a pre-anesthetic dose of ethyl ether and then were completely anesthetized with $10 \%$ chloral hydrate $(0.4 \mathrm{ml} / \mathrm{kg})$ by the peritoneal route. After abdominal trichotomy and antisepsis using topical iodopovidine, a median $5-\mathrm{cm}$ laparotomy was carried out, moving the bowel to the right. The juxta-infrarenal por- tion of the abdominal aorta was identified, isolated and ligated using 7-zero polypropylene thread. The whole procedure was performed with the assistance of a microscope viewer (bench model, series 51314; DF Vasconcellos, São Paulo, SP, Brazil) at 25X magnification. Ligature efficacy was confirmed by the paleness of the hind limbs when observed with the microscope viewer and the absence of a pulse below the ligature. Next, the intestines were repositioned in the cavity and the abdominal wall was closed using 3-zero cotton thread in a continuous single-plane suture.

\section{Animal randomization}

Six hours later the animals were re-operated upon and a random selection was performed via sealed envelopes to divide the animals into three groups of 6 rats each.

Group I (simple ischemia). Without removing the ligature of the aorta, $3 \mathrm{ml}$ of blood was collected from the animal's inferior vena cava. Next, two samples of the gastrocnemius muscle were withdrawn from the left hind limb, and the kidneys and lungs were also removed. Euthanasia was performed with an anesthetic overdose.

Group II (ischemia and reperfusion). The ligature of the animal's aorta was undone, allowing reperfusion of the hind limbs. Three milliliters of blood from the animal's inferior vena cava was collected, and the same puncture was utilized for the infusion of $3 \mathrm{ml}$ of $0.9 \%$ physiological saline for volume replacement. The bowel was again positioned and the abdomen closed. Twenty-four hours later, the animals were again anesthetized and reopened and $3 \mathrm{ml}$ blood was collected from the inferior vena cava. Two samples were removed from the gastrocnemius muscle of the left hind limb, and the kidneys and lungs were removed. Euthanasia was performed with an anesthetic overdose.

Group III (ischemia and reperfusion using anti-ICAM-1 antibodies). Procedures 
were exactly the same as in group II up to the phase of the infusion of $3 \mathrm{ml}$ of $0.9 \%$ physiological saline into the inferior vena cava after the second laparotomy. In this group, anti-ICAM-1 antibodies (ICN Biomedicals, Inc., Costa Mesa, CA, USA; clone 1A29, cat No. 69-627, lot No. 75606, control R37) were added and diluted to a concentration of $0.2 \mathrm{ml} / \mathrm{kg}$ in $3 \mathrm{ml}(\sim 10 \mathrm{ng} / \mathrm{ml})$ of $0.9 \%$ physiological saline. From this point on, the procedure was again identical to that of group II.

\section{Laboratory tests}

The blood obtained from the inferior vena cava was added to three different tubes. One milliliter was added to a tube containing EDTA as anticoagulant for leukocyte and differential counting; $1.5 \mathrm{ml}$ was added to a dry tube for creatine phosphokinase (CPK, in unit/l), lactate dehydrogenase ( $\mathrm{LDH}$, in unit/l), potassium (in $\mathrm{mEq} / \mathrm{l}$ ) and creatinine (in $\mathrm{mg} / \mathrm{dl}$ ) determination, and $0.5 \mathrm{ml}$ was added to a heparinized syringe for $\mathrm{pH}$ measurement.

The leukocyte count was performed with an automated laser flux cytometry analyzer (Cell Dyn 3700 or 4000, Abbott Diagnostic Division Cell-Dyn Systems, Santa Clara, CA, USA) and the differential count was confirmed by reading a microslide stained with Giemsa. To assess the $\mathrm{pH}$, the sample was submitted to a selective ion technique using an ABL5 Radiometer ${ }^{\circledR}$ gas analyzer (Diamond Diagnostics, Holliston, MA, USA). The blood stored in the dry tube was centrifuged at $45 \mathrm{~g}$ for $4 \mathrm{~min}$, and the plasma separated. All measurements were made using automatic and specific laboratory analyzers. Potassium was assessed by the selective ion method using a Hitachi 917- Roche ${ }^{\circledR}$ apparatus (Basel, Switzerland). Creatinine, CPK and LDH were accessed by enzymatic method on a Hitachi 917- Roche ${ }^{\circledR}$. All reagents were from Roche ${ }^{\circledR}$, and were specific for the reactions on these laboratory machines.

\section{Organ samples}

Two 1-mm samples obtained from the gastrocnemius of the left hind limb were weighed and frozen at $-80^{\circ} \mathrm{C}$ for myeloperoxidase analysis.

Kidneys and lungs were removed with their respective hila. The kidneys were split longitudinally and four samples were cut from each animal. Two samples were fixed in Bouin's for $12 \mathrm{~h}$, washed in running $0.9 \%$ physiological saline and transferred to $10 \%$ formaldehyde for later histological analysis. Two samples were weighed and snap frozen at $-80^{\circ} \mathrm{C}$ for extraction of myeloperoxidase.

The lungs were also sectioned longitudinally to produce four samples. Two samples were fixed in $10 \%$ formaldehyde for histological analysis, and the two remaining samples were weighed and snap frozen at $-80^{\circ} \mathrm{C}$ for extraction of myeloperoxidase.

\section{Myeloperoxidase extraction from tissue}

The material was thawed at room temperature and $0.5 \mathrm{ml}$ of the cell membrane detergent cetyldimethylethyl-ammonium bromide (L-5335, lot 26H03542; Sigma, St. Louis, MO, USA) was added for $20 \mathrm{~min}$. The samples were homogenized and left to stand for 30 min to optimize the enzymatic extraction. Thereafter, the material was centrifuged at $450 \mathrm{~g}$ for $20 \mathrm{~min}$ and the supernatant was separated and snap frozen at $-80^{\circ} \mathrm{C}$ for later enzyme reading with a spectrophotometer.

\section{Tissue myeloperoxidase reading}

The supernatant of the homogenized material was thawed and $450 \mu 1$ of 3,4,5trimethoxybenzoic acid, 8-diethylamineoctyl ester liquid substrate for ELISA (Dako, Barcelona, Spain) was added and read at 650 $\mathrm{nm}$ with a spectrophotometer. The results were plotted as a reference curve, with myeloperoxidase activity on one axis and the corresponding numbers of neutrophils on 
the other axis. The numbers obtained were then divided by the previously recorded weight of the material, thereby providing the number of neutrophils by per unit weight for each tissue of each group studied.

\section{Myeloperoxidase reference curve}

The total blood from 14 normal rats was collected in heparinized tubes. PMN were separated in a $50-\mathrm{ml}$ plastic beaker containing a cell sedimentation filter layer made up of 8 volumes $2 \%$ methylcellulose (Sigma) and 5 volumes $34 \%$ sodium hypaque (Sanofi Winthrop, Gentilly, France). After 20 min at room temperature, $50 \%$ of the plasma layer containing a large amount of leukocytes and platelets was transferred to a plastic tube, which was centrifuged at $30 \mathrm{~g}$ for $10 \mathrm{~min}$ at room temperature. The supernatant plasma, containing a large amount of platelets, was discarded and the cell sediment was carefully resuspended in PBS, pH 7.2, and centrifuged twice at $30 \mathrm{~g}$ for $10 \mathrm{~min}$. The supernatant was discarded and the cell sediment was mixed with $2 \mathrm{ml}$ previously chilled hemolysis solution $\left(8.29 \mathrm{~g} / 1 \mathrm{NH}_{4} \mathrm{CL}+1.0 \mathrm{~g} /\right.$ $1 \mathrm{KHCO}_{3}$; Merck, Whitehouse Station, NJ, USA) and kept at $4^{\circ} \mathrm{C}$ for $5 \mathrm{~min}$. The tube was again centrifuged at $30 \mathrm{~g}$ for $10 \mathrm{~min}$ at room temperature, the supernatant was discarded and the cells were resuspended in PBS and centrifuged at $30 \mathrm{~g}$ at room temperature. The cells were then resuspended in 1 $\mathrm{ml}$ PBS. The PMN were counted in a Neubauer chamber and diluted at a concentration of $7.5 \times 10^{6}$ cells $/ \mathrm{ml}$. We utilized the method of Bradley et al. (14) for the construction of the reference curve.

\section{Histological analysis of the kidneys}

Thin sections were obtained from paraffin blocks and stained with hematoxylineosin for structural analysis and PMN quantification under the light microscope. Other thin sections were treated with peroxidase- labeled anti-myoglobin antibodies to determine the presence of myoglobin in the renal tubules and glomeruli.

\section{Histological analysis of the lungs}

Sections cut from paraffin blocks were stained with hematoxylin-eosin and analyzed for structural alterations and quantification of the inflammatory infiltrate in the tissue.

\section{Statistical analysis}

ANOVA was used for the analysis of multiple variables. Values of $\mathrm{P} \leq 0.05$ with a $95 \%$ confidence interval were considered to be statistically significant.

\section{Results}

Tissue PMN concentrations are presented in Table 1. There were no variations in muscles from animals within the same group. However, there was a significant increase in the number of neutrophils/mg in the animals of group II - reperfusion $\left(1451 \pm 235 \times 10^{2}\right.$ neutrophils $/ \mathrm{mg}$ ) compared to the animals of group I - ischemia $\left(265 \pm 56 \times 10^{2}\right.$ neutrophils/mg, $\mathrm{P}<0.0001)$ and group III - antiICAM $\left(352 \pm 70 \times 10^{2}\right.$ neutrophils $/ \mathrm{mg}$, $\mathrm{P}<0.0005)$. A significantly higher neutrophil concentration was detected in group III compared to group I $(\mathrm{P}<0.019)$.

The kidneys showed no variation among animals within the same group. However, there was an increase in the concentration of inflammatory cells in group II $(852 \pm 73 \times$ $10^{2}$ neutrophils $/ \mathrm{mg}$ ) compared to group III $\left(526 \pm 89 \times 10^{2}\right.$ neutrophils $\left./ \mathrm{mg}, \mathrm{P}<0.001\right)$, in group III compared to group I $(353 \pm 53 \times$ $10^{2}$ neutrophils $\left./ \mathrm{mg}, \mathrm{P}<0.007\right)$ and in group II in relation to group I $(\mathrm{P}<0.0002)$.

The lungs showed no variation among animals within the same group or between groups (group I: 16,861 $\pm 13,226$, group II: $17,340 \pm 16,767$, and group III: $16,125 \pm$ $16,227 \times 10^{2}$ neutrophils/mg). There was no 
statistically significant difference among groups.

\section{Statistical analysis}

The results of the laboratory tests for creatinine, serum CPK and leukocytes showed no variation between the groups studied.

\section{Histological and immunohistochemical analysis of the kidneys}

No major histological lesions were detected in any animal (Figure 1). There was no myoglobin deposited in the glomeruli or in the tubules (Figure 2).

\section{Histological analysis of the lungs}

Numerous PMN were observed in the alveolar septal capillaries of all animals (Figure 3).

\section{Discussion}

During muscle ischemia, important alterations in muscle metabolism can occur, causing an accumulation of xanthine and hypoxanthine. When oxygen is reintroduced, free radicals are formed, causing localized cell damage because of their extreme reactivity. This mechanism may activate the defense system of the organism or even reinforce its action $(15,16)$. The inflammatory response may be considered as the initiator of a set of events related to ischemia and reperfusion lesions (17) and the blockage of this process has been shown to be efficient in preventing them (18).

With revascularization, there is a "wash out" of the postischemic tissue, with transportation of free radicals and activated defense cells to the systemic circulation and distant organs.

In the present experimental model, partial ischemia of the hind limbs was induced by ligation of the aorta but not of its collateral vessels. This procedure appeared to mimic most closely situations frequently occurring in clinical practice (19). The hind limbs remained pale, cold and exhibited decreased muscle strength until the aorta was revascularized.

There was no variation in serum creatinine, potassium, $\mathrm{LDH}, \mathrm{CPK}$ or $\mathrm{pH}$ levels, confirming that no major metabolic changes had occurred. Furthermore, PMN sequestration was observed in the tissue of the animals of all groups after reperfusion. This appears to contradict the peripheral counts, which were similar for all groups. Leukopenia was expected during the first 4 to $6 \mathrm{~h}$ after reper-

Table 1. Neutrophil concentration per mg of tissue in the different groups.

\begin{tabular}{lrrr}
\hline Groups & Muscle & Kidney & Lung \\
\hline Group I, simple ischemia & $265 \pm 56$ & $353 \pm 53$ & $16,861 \pm 13,226$ \\
Group II, ischemia and reperfusion & $1451 \pm 235$ & $852 \pm 73$ & $17,340 \pm 16,767$ \\
Group III, reperfusion with anti-ICAM-1 & $352 \pm 70$ & $526 \pm 89$ & $16,125 \pm 16,227$
\end{tabular}

Data are reported as means \pm SEM of neutrophils $\times 10^{2}$ per $\mathrm{mg}$ tissue.

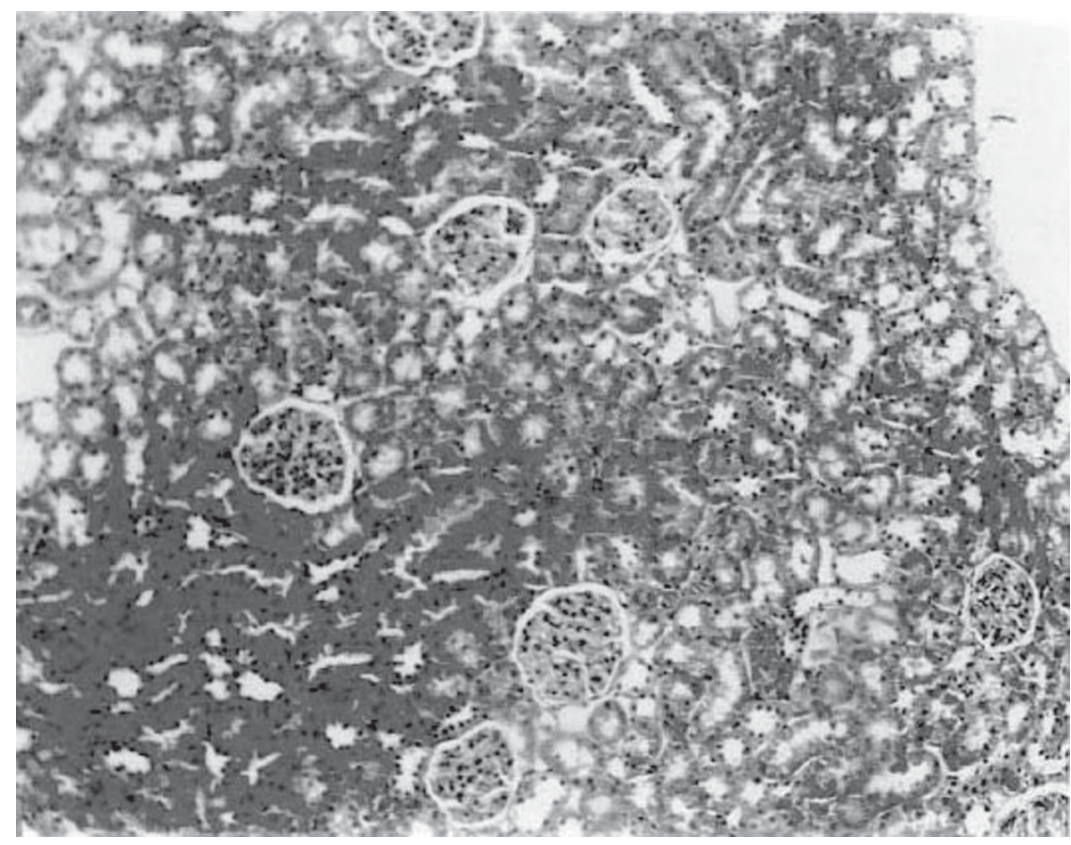

Figure 1. Histopathology of rat 3 (group I, simple ischemia). Note the absence of alterations in the nephrologic structure of the glomeruli, tubules, interstitium and vessels. There are no casts in the tubular lumina (HE, 400X). 
fusion, caused by leukocyte sequestration in tissue (20). However, over the subsequent hours, the white cell count returned to normal, probably because of bone marrow reactive hyperplasia (20). Blood collection coincided with this period, which was $24 \mathrm{~h}$ after reperfusion.

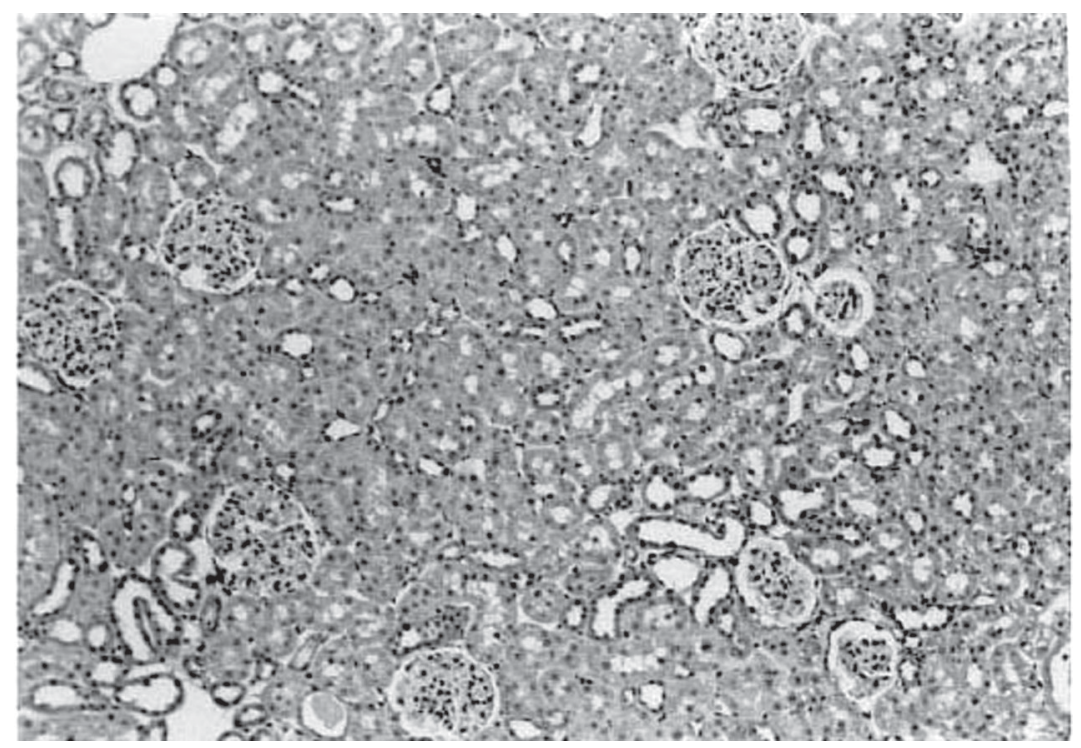

Figure 2. Immunohistochemistry for myoglobin in rat 13 (group III, anti-ICAM-1). Note the absence of myoglobin in Bowman's capsule and in the tubular lumina, either as casts or as traces (immunohistochemistry, 100X).

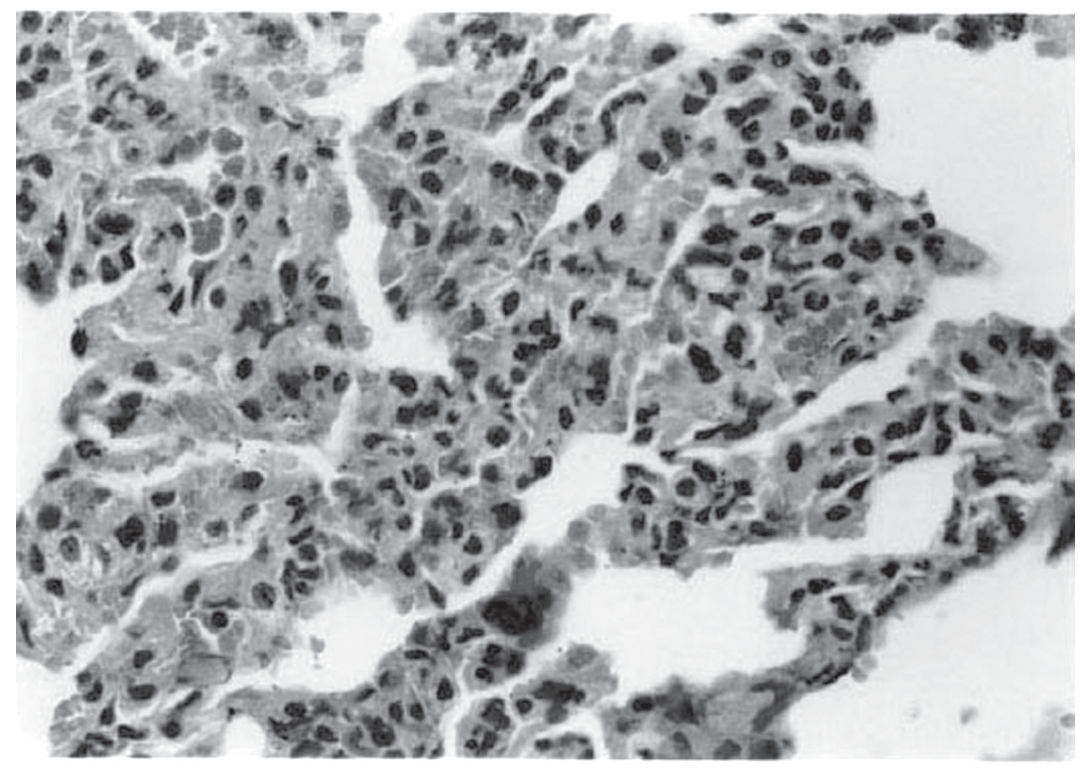

Figure 3. Histopathology of the lung of rat 8 (group II, reperfusion). The alveolar septa are thickened with edema and hypercellularity, mainly due to the neutrophil influx. The alveolar spaces are preserved (HE, 400X).
There were no major morphological alterations or deposits of myoglobin, probably because of the absence of muscle necrosis (21). There should have been sufficient time for filtration without impairment of renal function because of the small amounts of myoglobin released and the long interval before sample collection (22).

Since the 1982 study by Bradley et al. (14), it is generally agreed that the best way to quantify the acute inflammatory infiltrate is the measurement of neutrophil myeloperoxidase activity. The most notable results of our study were obtained with this method.

High myeloperoxidase activity was found in the lungs of all groups. Actually, this could have been expected because of the large concentration of inflammatory cells observed by histology even in untreated animals.

The variation of the pulmonary myeloperoxidase activity was probably due to the large amount of intravascular blood normally present in the lungs which interfered with the measurement of neutrophil influx (23).

In a similar experimental model, Engles et al. (24) observed a high pulmonary myeloperoxidase activity that did not differ significantly from control and explained this finding on the basis of the fact that the lungs had various activation mechanisms for their defense system. The interleukins, particularly interleukin 10, and tumor necrosis factor (TNF), via the complement system, may act directly on the pulmonary vascular endothelium (25) leading to an ICAM-1-independent mechanism of PMN chemotaxis. However, other studies have reported conflicting results. While an investigation demonstrated protection with the use of integrin blockers such as CD11/18 (26), the individual blockage of each system does not appear to significantly influence the PMN infiltrate during the reperfusion syndrome (27) or even with specific lung reperfusion (26), although studies have generally indicated that PMN have an important role in the genesis of 
lesions $(28,29)$. The lungs appear to be well adapted to the presence of toxic oxygen derivatives (30). Therefore, the conclusion regarding the lungs is that a large amount of inflammatory cells were present physiologically and that the selective blockage of some activation pathways, such as ICAM-1, did not alter this picture (31). This peculiarity seems to be very useful for organs in contact with the external environment, since they need an extremely efficient defense system.

The initial retention peak of neutrophils after ischemia, at $10 \mathrm{~min}$, is dependent on TNF- $\alpha$, which returns to normal levels practically within $4 \mathrm{~min}$ of reperfusion (32). Other studies have demonstrated the role of PMN in muscle lesions after ischemia by the deleterious effect of the release of free radicals, and their migration through the endothelium promoted by ICAM-1 (33). The use of inhibitors of adhesion molecules minimizes the reperfusion lesions by reducing PMN fixation on postischemic muscles of experimental models (34), as also observed in the present study.

The kidneys physiologically show ICAM-1 in the endothelium of the glomerular and peritubular capillaries (35). During cell injury, the renal tubules themselves present high ICAM-1 levels, thus showing that they are preferential sites for inflammatory response (36). Proinflammatory cytokines such as TNF- $\alpha$, interleukins 1 and 8 and interferon- $\gamma$ stimulate mesangial cell cultures of human kidneys, which present adhesiveness to PMN, probably acting via ICAM-1 (37). Although there is no consensus in the literature regarding these observations (38), they seem to indicate this pathway as one of the most important lesional mechanism in ischemia and renal reperfusion (39).

In a lower torso ischemia and reperfusion experimental model, some investigators found an increase in ICAM-1 in renal tubules, especially where there was deposition of myoglobin (40). They raised the hypothesis that the acute tubular necrosis observed in myoglobinuria may be secondary to the PMN infiltrate related to this adhesion molecule. In any event, the infiltrate of inflammatory cells mediated by ICAM appears to be the common pathway for the lesions (40). The present data allow us to conclude that the selective blockage of ICAM-1 in the kidneys effectively reduced the accumulation of PMN.

\section{References}

1. Bywaters EGL \& Beall D (1941). Crush injuries with impairment of renal function. British Medical Journal, 1: 427-432.

2. Haimovici H (1973). Myopathic-nephrotic-metabolic syndrome associated with massive acute arterial occlusions. Archives of Surgery, 106: 628-633

3. Ward MH (1988). Factors predictive of acute renal failure in rhabdomyolysis. Archives of Internal Medicine, 148: 1553-1557.

4. Hearse DJ, Humphrey WG \& Bucco GR (1978). The oxygen paradox and the calcium paradox: two facets of the same problem? Journal of Molecular and Cellular Cardiology, 10: 641-668.

5. McCord JM (1985). Oxygen-derived free radical in post-ischemic tissue injury. New England Journal of Medicine, 312: 159-163.

6. Weinbroum AA, Hochhauser E, Rudick V, Kluger Y, Karchevsky E, Graf E \& Vidne BA (1999). Multiple organ dysfunction after remote circulatory arrest: common pathway of radical oxygen species? Journal of Trauma, 47: 691-698.

7. Weiss SJ (1989). Tissue destruction by neutrophils. New England Journal of Medicine, 320: 365-376.

8. Rabb H, O'Meara YM, Maderna P, Coleman P \& Brady HR (1997).
Leukocytes, cell adhesion molecules and ischemic acute renal failure. Kidney International, 51: 1463-1468.

9. Welbourn CRB, Goldman G, Paterson IS, Valeri CR, Shepro D \& Hechtman HB (1991). Pathophysiology of ischaemia reperfusion injury: central role of the neutrophil. British Journal of Surgery, 78 : 651-655.

10. Rothlein R, Dustin ML, Marlin SD \& Springer TA (1986). A human intercellular adhesion molecule (ICAM-1) distinct from LFA-1. Journal of Immunology, 137: 1270-1278.

11. Diamond MS, Staunton DE, Fougerolles R, Stackers S, Garcia-Aguilar J, Hibbs ML \& Sprinter T (1990). ICAM-1 (CD54): a counter-receptor for Mac-1 (CD11/CD18). Journal of Cell Biology, 111 (Part 2): 31293139

12. Slater MS \& Mullins RJ (1998). Rhabdomyolysis and myoglobinuric renal failure in trauma and surgical patients: a review. Journal of the American College of Surgeons, 186: 693-716.

13. Seekamp A \& Ward PA (1993). Ischemia-reperfusion injury. Agents and Actions, 41 (Suppl): 137-152.

14. Bradley PP, Priebat DA, Christensen RD \& Rothstein G (1982). 
Measurement of cutaneous inflammation: estimation of neutrophil content with an enzyme marker. Journal of Investigative Dermatology, 78: 206-209.

15. Defraigne JO \& Pincemail J (1997). Local and systemic consequences of severe ischemia and reperfusion of the skeletal muscle: physiopathology and prevention. Acta Chirurgica Belgica, 97: 176186.

16. Babior BM (2000). Phagocytes and oxidative stress. American Journal of Medicine, 109: 33-44.

17. Cambria RA, Anderson RJ, Dikdan G, Teehan EP, HernandezMaldonado JJ \& Hobson RW (1991). Leukocyte activation in ischemia-reperfusion injury of skeletal muscle. Journal of Surgical Research, 51: 13-17.

18. Carden DL, Smith JK \& Korthuis RJ (1990). Neutrophil-mediated microvascular dysfunction in post-ischemic canine skeletal muscle. Role of granulocyte adherence. Circulation Research, 66: 14361444.

19. Maffei FHA, Lastoria S, Yoshida WB \& Rollo HA (1995). Doenças Vasculares Periféricas. 2nd edn. Medsi, Rio de Janeiro, RJ, Brazil.

20. Welbourn R, Goldman G, Kobzik L, Paterson IS, Valeri CR, Shepro D \& Hechtman HB (1992). Role of neutrophil adherence receptors (CD18) in lung permeability following lower torso ischemia. Circulation Research, 71: 82-86.

21. Kadambi A \& Skalak TC (2000). Role of leukocytes and tissuederived oxidants in short-term skeletal muscle ischemia-reperfusion injury. American Journal of Physiology, 278: H435-H443.

22. Bless NM, Warner RL, Padgaonkar VA, Lentsch AB, Czermak BJ, Schmal H, Friedl HP \& Ward PA (1999). Roles for C-X-C chemokines and $\mathrm{C} 5 \mathrm{a}$ in lung injury after hind limb ischemia-reperfusion. American Journal of Physiology, 276 (Part 1): L57-L63.

23. Anderson BO, Brown JM, Shanley PF, Bensard DD \& Harken AH (1991). Marginating neutrophils are reversibly adherent to normal lung endothelium. Surgery, 109: 51-61.

24. Engles RE, Huber TS, Zander DS, Hess PJ, Welbourn MB, Moldawer LL \& Seeger JM (1997). Exogenous human recombinant interleukin10 attenuates hind limb ischemia-reperfusion injury. Journal of Surgical Research, 69: 425-428.

25. Horgan MJ, Ge M, Gu J, Rothlein R \& Malik AB (1991). Role of ICAM-1 in neutrophil-mediated lung vascular injury after occlusion and reperfusion. American Journal of Physiology, 261 (Part 2): H1578-H1584.

26. Horgan MJ, Wright SD \& Malik AB (1990). Antibody against leukocyte integrin (CD18) prevents reperfusion-induced lung vascular injury. American Journal of Physiology, 259 (Part 1): L315-L319.

27. Stammberger U, Carboni GL, Hillinger S, Schneiter D, Weder W \& Schmid RA (1999). Combined treatment with endothelin and PAFantagonists reduces post-transplant lung ischemia/reperfusion injury. Journal of Heart and Lung Transplantation, 18: 862-868.

28. Levine AJ, Parkes K, Rooney S \& Bonser RS (2000). Reduction of endothelial injury after hypothermic lung preservation by initial leukocyte-depleted reperfusion. Journal of Thoracic and Cardiovascular Surgery, 120: 47-54.

29. Carden D, Xiao F, Moak C, Willis BH, Robinson-Jackson S \& Alexander $S$ (1998). Neutrophil elastase promotes lung microvascular injury and proteolysis of endothelial cadherins. American Journal of Physiology, 275 (Part 2): H385-H392.

30. Vural KM \& Oz MC (2000). Endothelial adhesivity, pulmonary hemodynamics and nitric oxide synthesis in ischemia-reperfusion. European Journal of Cardio-Thoracic Surgery, 18: 348-352.

31. Kyrikiades C, Austen Jr WG, Wang W, Favuzza J, Moore FD \& Hechtman HB (2000). Neutrophil mediated remote organ injury after lower torso ischemia and reperfusion is selection and complement dependent. Journal of Trauma, 48: 32-38.

32. Eppinger MJ, Deeb GM, Bolling SF \& Ward PA (1997). Mediators of ischemia-reperfusion injury of rat lung. American Journal of Pathology, 150: 1773-1784.

33. Lazarus B, Messina A, Barker JE, Hurley JV, Romeo R, Morrison WA \& Knight KR (2000). The role of mast cells in ischaemia-reperfusion injury in murine skeletal muscle. Journal of Pathology, 191: 443-448.

34. Petrasek PF, Liauw S, Romanschin AD \& Walker PM (1994). Salvage of postischemic skeletal muscle by monoclonal antibody blockade of neutrophil adhesion molecule CD18. Journal of Surgical Research, 56: 5-12.

35. Bishop GA \& Hall BM (1989). Expression of leukocyte and lymphocyte adhesion molecules in the human kidney. Kidney International, 36: 1078-1085

36. Andersen CB, Blaehr H, Ladefoged S \& Larsen S (1992). Expression of the intercellular adhesion molecule-1 (ICAM-1) in human renal allografts and cultured human tubular cells. Nephrology, Dialysis, Transplantation, 7: 147-154

37. Denton MD, Marsden PA, Luscinskas FW, Brenner BM \& Brady HR (1991). Cytokine-induced phagocyte adhesion to human mesangial cells: role of CD11/CD18 integrins and ICAM-1. American Journal of Physiology, 261 (Part 2): F1071-F1079.

38. Kelly KJ, Williams Jr WW, Colvin RB, Meehan SM, Springer TA, Gutierrez-Ramos JC \& Bonventre JV (1996). Intercellular adhesion molecule-1-deficient mice are protected against ischemic renal injury. Journal of Clinical Investigation, 97: 1056-1063.

39. Kelly KJ, Williams Jr WW, Colvin RB \& Bonventre JV (1994). Antibody to intercellular adhesion molecule 1 protects the kidney against ischemic injury. Proceedings of the National Academy of Sciences, USA, 91: 812-816.

40. Kelly KJ, Tolkoff-Rubin NE, Rubin RH, Williams Jr WW, Meehan SM, Meschter CL, Christenson JG \& Bonventre JV (1996). An oral platelet-activating factor antagonist, Ro-24-4736, protects the rat kidney from ischemic injury. American Journal of Physiology, 271 (Part 2): F1061-F1067. 